\title{
A Retrospective Study of LDL-Cholesterol in Koreans on Atorvastatin/Ezetimibe or Atorvastatin Monotherapy
}

Sang-Hyun Ihm ${ }^{1}$, Jung-Sun Kim ${ }^{2}$, Chang-Hwan Yoon ${ }^{3}$, Sung-Ho Her ${ }^{4}$, Chang-Wook Nam ${ }^{5}$, Jin Won Kim ${ }^{6}$, Jang-Whan Bae $^{7}$, Sung Uk Kwon ${ }^{8}$, Doo-Soo Jeon ${ }^{9}$, Jong-Min Lee ${ }^{10}$, Byung-Hee Hwang ${ }^{11}$, Hyun Won Shin ${ }^{12}$, Kiyuk Chang ${ }^{11^{*}}$

${ }^{1}$ Division of Cardiology, Bucheon St. Mary's Hospital, The Catholic University of Korea, Bucheon, South Korea

${ }^{2}$ Division of Cardiology, Yonsei University Severance Hospital, Seoul, South Korea

${ }^{3}$ Cardiovascular Center, Seoul National University Bundang Hospital, Seongnam, South Korea

${ }^{4}$ Department of Cardiology, Daejeon St. Mary's hospital, College of Medicine, The Catholic University of Korea, Seoul, Republic of Korea

${ }^{5}$ Division of Cardiology, Department of Internal Medicine, Keimyung University Dongsan Hospital, Daegu, South Korea

${ }^{6}$ Division of Cardiology, Korea University Guro Hospital, Seoul, South Korea

${ }^{7}$ Department of Internal Medicine, Chungbuk National University College of Medicine, Cheongju, Republic of Korea

${ }^{8}$ Vision 21 Cardiac and Vascular Center, Inje University Ilsan Paik Hospital, Goyang, South Korea

${ }^{9}$ Division of Cardiology, Incheon St. Mary's Hospital, The Catholic University of Korea, Incheon, South Korea

${ }^{10}$ Division of Cardiology, Uijeongbu St. Mary's Hospital, The Catholic University of Korea, Uijeongbu, South Korea

${ }^{11}$ Division of Cardiology, Seoul St. Mary's Hospital, The Catholic University of Korea, Seoul, South Korea

${ }^{12}$ MSD Korea Ltd, Seoul, South Korea

Received: October 31,2019; Accepted: November 7,2019; Published: November 13,2019

*Corresponding author : Pro. Kiyuk Chang, M.D, Ph.D., Division of Cardiology, Seoul St. Mary's Hospital, The Catholic University of Korea, 222 Banpo-daero, Seocho-gu, Seoul, 06591, South Korea; Tel: +82-2-2258-6032; Fax: +82-2-2258-1138; E-mail: kiyuk@catholic.ac.kr

\begin{abstract}
Purpose: To investigate low-density lipoprotein cholesterol (LDL-C) goal attainment rates in patients with hypercholesterolemia treated with atorvastatin/ezetimibe or atorvastatin monotherapy.

Methods: This was a multicenter, noninterventional, retrospective, chart review study of Korean patients with hypercholesterolemia who were statin-naïve and prescribed atorvastatin/ezetimibe or atorvastatin monotherapy during an observational period, from January 2014 to July 2017, and followed up for 12-18 weeks. Patients were propensity score matched to reduce treatment selection bias. Outcomes included LDL-C goal attainment rate at week 12, defined by risk groups according to Korean Society of Lipidology and Atherosclerosis guidelines; and change in lipid parameters from the index date to week 12.

Results: A total of 969 patients were enrolled in the study: atorvastatin/ezetimibe, $n=349$; atorvastatin monotherapy, $n=620$. Following propensity matching $(n=316$ in each group), respective LDL-C goal attainment rates for atorvastatin/ezetimibe and atorvastatin monotherapy groups were $86 \%$ and $75 \%$, respectively $(\mathrm{p}=0.0004)$. Atorvastatin/ezetimibe produced significantly larger reductions at week 12 in mean LDL-C $(-50.3 \%$ vs $-42.7 \%)$, total cholesterol $(-36.8 \%$ vs $-30.7 \%)$ and non-high-density lipoprotein cholesterol (non-HDL-C; $-47.3 \%$ vs $-39.8 \%$ ) levels compared to atorvastatin monotherapy (all $\mathrm{p}<0.0001$ ).
\end{abstract}

Conclusion: More patients achieved LDL-C goal attainment with atorvastatin/ezetimibe than with atorvastatin monotherapy, and atorvastatin/ ezetimibe was associated with significantly larger reductions in mean LDL-C, total cholesterol and non-HDL-C levels than atorvastatin monotherapy, in Korean patients with hypercholesterolemia in a real-world clinical practice.

Keywords: Hypercholesterolemia; Low-Density Lipoprotein C; Atorvastatin/Ezetimibe; Atorvastatin Monotherapy; Korean patients

\section{Introduction}

The Global Burden of Disease 2015 study estimated that during that year there were 422.7 million cases of cardiovascular disease (CVD) and 17.92 million CVD deaths worldwide [1]. Although there has been a dramatic decline in the age-standardized CVD

death rate between 1990 and 2015 in all high-income and some middle-income countries, many regions showed a gradual reduction or no change in CVD mortality during this period [1]. In Korea, despite a significant decrease in the total CVD mortality 
rate, deaths from ischemic heart disease have increased over a 30-year period (1983-2012) [2].

Hypercholesterolemia is widely recognized as a strong risk factor for CVD and lowering low-density lipoprotein cholesterol (LDL-C) is a primary goal of therapy. Statins (HMG CoA reductase inhibitors) are the most effective LDL-C lowering drugs and are recommended in current blood cholesterol management guidelines [3].

A recent study of more than 12,000 adults who participated in the 2010-2012 Korea National Health and Nutrition Survey (KNHANES), reported an age-standardized prevalence for dyslipidemia of 39.6\% [4], which was defined using NCEP ATP III criteria as hyper-LDL-cholesterolemia or hypertriglyceridemia [5]. In addition, the 2015 KNHANES found that approximately onefifth of Korean adults aged $\geq 30$ years had hypercholesterolemia, defined as serum total cholesterol level $\geq 240 \mathrm{mg} / \mathrm{dL}$ or the use of lipid-lowering medications [6].

Despite the availability of statins, many patients with stable or acute coronary heart disease (CHD) fail to achieve LDL-C targets. Recent results from the Dyslipidemia International Study II (DYSIS II) of patients in the Asia-Pacific region showed that $69 \%$ of patients with stable CHD failed to achieve LDL-C $<70 \mathrm{mg} / \mathrm{dL}$ and $77 \%$ of patients with acute coronary syndrome (ACS) failed to achieve their LDL-C targets [7]. In Korean patients in the DYSIS II study, $57 \%$ of CHD patients and $62 \%$ of ACS patients failed to achieve their LDL-C targets after 4 months of treatment $[8,9]$.

Concomitant administration of ezetimibe and a statin achieves more effective LDL-C reduction than statin monotherapy without increasing the risk of side effects from increased statin doses. A randomized clinical trial in 628 patients with primary hypercholesterolemia showed a greater reduction in LDL-C for combined atorvastatin/ezetimibe than for atorvastatin monotherapy [10]. More recently, data from the landmark IMPROVE-IT trial, in high-risk post-ACS patients, showed that ezetimibe $10 \mathrm{mg} /$ simvastatin $40 \mathrm{mg}$ significantly reduced LDL-C levels and the rate of long-term cardiovascular events compared with simvastatin $40 \mathrm{mg}$ monotherapy [11].

There is currently a lack of evidence for the effectiveness of atorvastatin/ezetimibe as a primary treatment for hypercholesterolemia in the real-world clinical practice setting in Korea. The objective of the current study was to investigate LDL-C goal attainment rates in statin-naïve patients with hypercholesterolemia treated with atorvastatin/ezetimibe or atorvastatin monotherapy in real-world clinical practice in Korea.

\section{Methods}

\section{Study Design}

This was a multicenter, noninterventional, retrospective, chart review study of patients with hypercholesterolemia treated with a combination of atorvastatin/ezetimibe or atorvastatin monotherapy. Medical records from patients enrolled at 12 sites in Korea were reviewed during the observational period, from January 2014 to July 2017, and those who were statin-naïve and initiated atorvastatin/ezetimibe or atorvastatin monotherapy within this period were enrolled. Patients were followed up for 12-18 weeks from the index date (date of starting treatment), with data collection beginning in August 2017. Data for lipid parameters were collected within 4 weeks prior to the index date and at 12-18 weeks from the index date.

\section{Inclusion and exclusion criteriaStudy Design}

AAdult statin-naïve patients with hypercholesterolemia aged $\geq 19$ years at the time of starting treatment with atorvastatin/ezetimibe $(10 / 10 \mathrm{mg}$ or $10 / 20 \mathrm{mg}$ ) or atorvastatin monotherapy (10 mg or $20 \mathrm{mg}$ ), between January 2014 and July 2017, were included in the study. Patients were also required to receive treatment with atorvastatin/ezetimibe or atorvastatin monotherapy for at least 12 weeks by July 2017, and have lipid profile results (LDL-C, total cholesterol, triglyceride, and high-density lipoprotein cholesterol [HDL-C]) available at both the index date and at 12 weeks from treatment initiation.

Main exclusion criteria were: patients who had received statin treatment, other than atorvastatin, during the 12-week followup period; a very high triglyceride level $(\geq 500 \mathrm{mg} / \mathrm{dL}$ ) or low LDL-C level $(<70 \mathrm{mg} / \mathrm{dL})$ at the index date; patients with severe acute liver disease or severe renal failure; and patients who were prescribed atorvastatin/ezetimibe or atorvastatin for an unapproved indication.

\section{Efficacy analyses}

The primary efficacy outcome was the LDL-C goal attainment rate at week 12. This outcome was defined by LDL-C goals in risk groups according to the 2015 Korean Society of Lipidology and Atherosclerosis (KSLA) guidelines [12] as follows: very high risk $<70 \mathrm{mg} / \mathrm{dL}$, high risk $<100 \mathrm{mg} / \mathrm{dL}$, moderate risk $<130 \mathrm{mg} / \mathrm{dL}$, and low risk $<160 \mathrm{mg} / \mathrm{dL}$.

Secondary efficacy outcomes were the percentage change in LDL-C, HDL-C, total cholesterol, triglyceride and non-HDL-C levels from the index date to week 12.

The goal attainment rate and changes in lipid parameters were assessed on both unmatched and propensity score matched treatment groups (see Statistical Analysis).

An exploratory analysis of the goal attainment rate and change in lipid parameters was performed in hypercholesterolemia patients with concurrent diabetes.

\section{Statistical analysis}

Continuous data were summarized using descriptive statistics (number of subjects, mean, standard deviation [SD], median, minimum, maximum) and compared using Student's t-test. Categorical data were summarized using frequency and percentage and compared by the chi-squared test. For the difference in LDL-C goal attainment rate between two treatment groups, statistical significance was determined using the chisquared test.

Results for the rate of change in lipid parameters were expressed as least square mean (LSM) and standard error (SE) for each treatment, and LSM difference with SE and 95\% CI. Differences 
between the two treatment groups for lipid parameters were calculated by analysis of covariance (ANCOVA) with adjusting baseline characteristics (unmatched groups) and paired t-tests (matched groups).

All statistical analyses were performed as two-tailed tests at a $5 \%$ significance level and carried out using SAS Software version 9.4 or higher.

Propensity score matching was conducted to reduce treatment selection bias in the two treatment groups due to confounding variables including age, sex, center, baseline LDL-C, risk classification, statin dosage, diabetes and other comorbidities. The propensity score was calculated using a logistic regression model using 1:1 nearest neighbor greedy algorithm [13], with baseline lipid parameters, risk classification defined by the 2015 KSLA guidelines [12] and diabetes used as covariates in propensity score matching and ANCOVA.

\section{Determination of Sample Size}

Sample size was calculated from estimation of goal attainment rates, the proportion of dyslipidemia patients with diabetes, and the proportion of discarded patients following propensity score matching.

The goal attainment rates in two randomized controlled trials which compared statin monotherapy with statin/ezetimibe combination therapy were $73 \%$ versus $85 \%$ [10] and $68 \%$ versus $86 \%$ [14], respectively. For calculation of the sample size, we conservatively estimated goal attainment rates of $70 \%$ and $85 \%$ for statin monotherapy and statin/ezetimibe combination therapy, respectively. Sample size calculation, using PASS $12 \AA$ software, showed that a minimum of 242 patients (121 in each group) would attain $80 \%$ power at a $5 \%$ significance level for a two-tailed test of the null hypothesis that the two treatment groups had similar goal attainment rates.

The proportions of dyslipidemia patients who had concurrent diabetes in the ACTFAST-2 [15], ATGOAL [16], and IMPROVE IT [17] studies were reported as $27-44 \%$. Assuming that the proportion of dyslipidemia patients who had concurrent diabetes was $27 \%$, the calculated number of dyslipidemia patients needed for enrollment (in order to include 242 patients with concurrent diabetes) was 898 .

The proportion of discarded patients after propensity score matching was conservatively estimated to be $30 \%$. On this basis, the final sample size was calculated as 1,284 patients (642 per group).

\section{Results}

Following screening, 51 subjects $(n=21$, atorvastatin/ezetimibe group; $\mathrm{n}=30$, atorvastatin monotherapy group) were excluded due to: failure to meet inclusion/exclusion criteria in 32 subjects $(\mathrm{n}=18$ atorvastatin/ezetimibe group; $\mathrm{n}=14$, atorvastatin monotherapy group), lipid test at week 12 performed more than 3 days after the last administration of the study drug in 14 subjects $(n=3$, atorvastatin/ezetimibe group; $n=11$ atorvastatin monotherapy group), dose modification during the study in 2 subjects ( $\mathrm{n}=2$, atorvastatin monotherapy group), and 3 subjects who were non-Korean ( $\mathrm{n}=3$, atorvastatin monotherapy group).

A total of 969 subjects ( 349 subjects in the atorvastatin/ezetimibe group and 620 subjects in the atorvastatin monotherapy group) were enrolled in this study, all of whom were included in analyses.

\section{Demographic and baseline characteristics}

Demographic and baseline characteristics of subjects in the study population are summarized in Table 1 . The mean (SD) age of all subjects was 59.0 (11.8) years, of whom $47.3 \%$ were male. Subjects had a mean (SD) body mass index of 24.9 (3.4) kg/m2 and approximately half of all patients were non-smokers (53.6\%) and non-drinkers (46.1\%). Significant differences between the atorvastatin/ezetimibe and atorvastatin groups were found for mean systolic blood pressure (SBP; 129.1 versus $125.7 \mathrm{mmHg}$ ) and diastolic blood pressure (DBP; 78.3 versus $75.9 \mathrm{mmHg}$ ) (each $p=0.003$ ). However, SBP and DBP were not used as covariates for risk propensity score matching as hypertension was included as a major risk factor in risk classification.

There was also a statistically significant inter-group difference in the risk level of subjects $(p=0.034)$. The proportion of subjects with very high risk (LDL-C goal $<70 \mathrm{mg} / \mathrm{dL}$ ) was higher in the atorvastatin/ezetimibe group compared with the atorvastatin group (29.8\% versus $26.0 \%$ ); lower in high (LDL-C goal $<100$ $\mathrm{mg} / \mathrm{dL} ; 24.9 \%$ versus $31.3 \%$ ) and intermediate risk subjects (LDL-C goal <130 mg/dL; $20.1 \%$ versus $23.2 \%$ ); and higher in low risk subjects (LDL-C goal $<160 \mathrm{mg} / \mathrm{dL} ; 25.2 \%$ versus $19.5 \%$ ) (Table 1).

Data regarding past medical history were available for $60.1 \%$ of subjects $(\mathrm{n}=582)$. The most common condition (categorized by System Organ Class) was a history of cardiac disorders ( $\mathrm{n}=116$; $12.0 \%)$, followed by gastrointestinal disorders $(n=102 ; 10.5 \%)$, and endocrine disorders (excluding diabetes, $\mathrm{n}=96 ; 9.9 \%$ ) and neoplasms benign, malignant and unspecified (including cysts and polyps) ( $\mathrm{n}=96 ; 9.9 \%$ ) (Table 1$)$.

By Preferred Term, the most common disorder was gastroesophageal reflux disease (GERD) $(n=46 ; 4.8 \%)$, followed by atrial fibrillation $(n=45 ; 4.6 \%)$, and hypothyroidism $(n=37$; $3.8 \%$ ) (Table 1).

A total of 775 subjects $(80.0 \%)$ had a risk of CVD, of which hypertension was the most common $(\mathrm{n}=523 ; 54.0 \%)$, followed by diabetes $(\mathrm{n}=355 ; 36.6 \%)$, and CHD $(\mathrm{n}=227 ; 23.4 \%)$ (Table 1). 


\begin{tabular}{|c|c|c|c|}
\hline Parameter & Atorvastatin/ezetimibe & Atorvastatin monotherapy & Total \\
\hline n (\%) & $349(36.0)$ & $620(64.0)$ & $969(100)$ \\
\hline Age (years): mean (SD) & $58.5(11.8)$ & $59.4(11.7)$ & $59.0(11.8)$ \\
\hline $\begin{array}{l}\text { Sex, male: n (\%) } \\
\quad \text { female: n (\%) }\end{array}$ & $\begin{array}{l}162(46.4) \\
187(53.6)\end{array}$ & $\begin{array}{l}296(47.7) \\
324(52.3)\end{array}$ & $\begin{array}{l}458(47.3) \\
511(52.7)\end{array}$ \\
\hline Body Mass Index $(\mathrm{kg} / \mathrm{m} 2):$ mean $(\mathrm{SD})^{\wedge}$ & $25.1(3.5)$ & $24.8(3.4)$ & $24.9(3.4)$ \\
\hline \multicolumn{4}{|l|}{ Smoking Status, n (\%) } \\
\hline Non-Smoker & $186(53.3)$ & $333(53.7)$ & $519(53.6)$ \\
\hline Smoker & $46(13.2)$ & $58(9.4)$ & $104(10.7)$ \\
\hline Ex-Smoker & $28(8.0)$ & $73(11.8)$ & $101(10.4)$ \\
\hline Unknown & $89(25.5)$ & $156(25.2)$ & $245(25.3)$ \\
\hline \multicolumn{4}{|l|}{ Drinking Status, n (\%) } \\
\hline Non-Drinker & $163(46.7)$ & $284(45.8)$ & $447(46.1)$ \\
\hline Drinker & $87(24.9)$ & $159(25.7)$ & $246(25.4)$ \\
\hline Unknown & $99(28.4)$ & 177 (28.6) & $276(28.5)$ \\
\hline Systolic blood pressure (mmHg): mean (SD) * & $129.1(17.0)$ & $125.7(15.9)$ & $126.9(16.3)$ \\
\hline Diastolic blood pressure (mmHg): mean (SD) * & $78.3(11.8)$ & $75.9(10.9)$ & $76.8(11.3)$ \\
\hline \multicolumn{4}{|l|}{ Risk Level, n (\%) † } \\
\hline Very high risk (LDL-C goal $<70 \mathrm{mg} / \mathrm{dL}$ ) & $104(29.8)$ & $161(26.0)$ & $265(27.4)$ \\
\hline High risk (LDL-C goal <100 mg/dL) & $87(24.9)$ & $194(31.3)$ & $281(29.0)$ \\
\hline Intermediate risk (LDL-C goal <130 mg/dL) & $70(20.1)$ & $144(23.2)$ & $214(22.1)$ \\
\hline Low risk (LDL-C goal <160 mg/dL) & $88(25.2)$ & $121(19.5)$ & $209(21.6)$ \\
\hline Medical history: n (\%) & $171(49.0)$ & $411(66.3)$ & $582(60.1)$ \\
\hline Cardiac disorders: $\mathrm{n}(\%)$ & $12(3.4)$ & $104(16.8)$ & $116(12.0)$ \\
\hline Atrial fibrillation: $\mathrm{n}(\%)$ & $4(1.2)$ & $41(6.6)$ & $45(4.6)$ \\
\hline Gastrointestinal disorders: n (\%) & $30(8.6)$ & $72(11.6)$ & $102(10.5)$ \\
\hline Gastroesophageal reflux disease: $\mathrm{n}(\%)$ & $13(3.7)$ & $33(5.3)$ & $46(4.8)$ \\
\hline Endocrine disorders: n (\%) & $24(6.9)$ & $72(11.6)$ & $96(9.9)$ \\
\hline Hypothyroidism: n (\%) & $10(2.9)$ & $27(4.4)$ & $37(3.8)$ \\
\hline $\begin{array}{l}\text { Neoplasms benign, malignant and unspecified } \\
\text { (including cysts and polyps): } \mathrm{n}(\%)\end{array}$ & $26(7.5)$ & $70(11.3)$ & $96(9.9)$ \\
\hline Cardiovascular Risk: n (\%) & $273(78.2)$ & $502(81.0)$ & $775(80.0)$ \\
\hline Hypertension: n (\%) & $191(54.7)$ & $332(53.6)$ & $523(54.0)$ \\
\hline Diabetes: n (\%) & $116(33.2)$ & $239(38.6)$ & $355(36.6)$ \\
\hline Coronary Heart Disease: n (\%) & $89(25.5)$ & $138(22.3)$ & $227(23.4)$ \\
\hline $\begin{array}{l}\text { Family history of premature coronary artery } \\
\text { disease: } n(\%)\end{array}$ & $18(5.2)$ & $22(3.6)$ & $40(4.1)$ \\
\hline \multicolumn{4}{|c|}{$\begin{array}{l}\text { ^Body Mass Index (BMI): } \mathrm{n}=305 \text {, atorvastatin/ezetimibe group; } \mathrm{n}=563 \text {, atorvastatin monotherapy group; } \mathrm{n}=868 \text {, total. } \\
\text { *Systolic Blood Pressure (SBP) and Diastolic Blood Pressure (DBP): } n=319 \text { atorvastatin/ezetimibe; } n=550 \text {, atorvastatin; } n=869 \text {, total. Significant } \\
\text { inter-group difference in SBP }(p=0.003) \text { and DBP }(p=0.003) \text {. } \\
\text { † Significant inter-group difference in risk level }(p=0.034) \text {. }\end{array}$} \\
\hline
\end{tabular}




\section{Propensity score matching}

The propensity scores of the two treatment groups were more similar after matching (Table 2). Before matching, mean (SD) scores in the atorvastatin/ezetimibe and atorvastatin monotherapy groups were $0.399(0.131)$ and $0.338(0.101)$, respectively. After matching, the respective scores were $0.373(0.106)$ and $0.373(0.105)$.

\begin{tabular}{|l|l|l|}
\hline \multicolumn{2}{|l|}{ Table 2: Propensity score matching. } \\
\hline Propensity score & Atorvastatin/ezetimibe $(\mathrm{N}=349)$ & Atorvastatin monotherapy $(\mathrm{N}=620)$ \\
\hline Unmatched: mean (SD) & $0.399(0.131)$ & $0.338(0.101)$ \\
\hline $\mathrm{n}$ & 349 & 620 \\
\hline Matched: mean (SD) & $0.373(0.106)$ & $0.373(0.105)$ \\
\hline $\mathrm{n}$ & 316 & 316 \\
\hline
\end{tabular}

\section{Efficacy analyses}

Rates of LDL-C goal attainment before and after propensity matching are summarized in Table 3. Goal attainment rates were 83\% and $79 \%$ in unmatched atorvastatin/ezetimibe $(n=349)$ and atorvastatin monotherapy $(n=620)$ groups, respectively. Following propensity matching $(\mathrm{n}=316$ in each group), the goal attainment rate was significantly higher in the atorvastatin/ezetimibe group than in the atorvastatin monotherapy group $(86 \%$ and $75 \%, \mathrm{p}=0.0004)$.

Significant differences between the two treatment groups were found for LDL-C, total cholesterol and non-HDL-C levels ( $p<0.0001$ for all), with atorvastatin/ezetimibe producing larger reductions in mean lipid levels than atorvastatin monotherapy (Table 4). These differences were identified in both unmatched (using ANCOVA) and propensity matched (using paired t-tests) groups. Mean percentage changes from the index date to week 12 in propensity matched atorvastatin/ezetimibe and atorvastatin monotherapy groups were $-50.3 \%$ and $-42.7 \%$, respectively, for LDL-C; $-36.8 \%$ and $-30.7 \%$ for total cholesterol; and $-47.3 \%$ and $-39.8 \%$ for non-HDL-C. There were no significant inter-group differences for HDL-C or triglycerides.

In hypercholesterolemia patients with diabetes, LDL-C goal attainment rates in unmatched atorvastatin/ezetimibe (n = 116) and atorvastatin monotherapy $(\mathrm{n}=239)$ groups were $0.77(95 \% \mathrm{CI}, 0.69-0.84)$ and $0.79(95 \% \mathrm{CI}, 0.74-0.85)$, respectively. In propensity matched groups $(\mathrm{n}=103$ for each), respective rates were 0.82 (95\% CI, 0.74-0.89] and 0.74 (95\% CI, 0.65-0.82).

No significant differences between the treatment groups in hypercholesterolemia patients with diabetes were found for change from baseline for any lipid parameter (LDL-C, HDL-C, non-HDL-C, total cholesterol or triglyceride) in unmatched or propensity matched groups. Mean percentage changes in propensity matched atorvastatin/ezetimibe and atorvastatin monotherapy groups $(\mathrm{n}=103)$ were $-47.0 \%$ and $-45.3 \%$, respectively, for LDL-C; $-0.6 \%$ and $0.2 \%$ for HDL-C; $-42.9 \%$ and $-41.6 \%$ for non-HDL-C; $-34.3 \%$ and $-32.4 \%$ for total cholesterol; and $-10.7 \%$ and $-12.8 \%$ for triglyceride.

\begin{tabular}{|c|c|c|}
\hline & Atorvastatin/ezetimibe & Atorvastatin monotherapy \\
\hline Week 12 (Unmatched): n & 349 & 620 \\
\hline Goal attainment incidence: $\mathrm{n}$ & 290 & 487 \\
\hline Goal attainment rate: ratio $[95 \% \mathrm{CI}]$ & $0.83[0.79-0.87]$ & $0.79[0.75-0.82]$ \\
\hline Week 12 (Matched): n & 316 & 316 \\
\hline Goal attainment incidence: $\mathrm{n}$ & 272 & 237 \\
\hline Goal attainment rate: ratio $[95 \% \mathrm{CI}]$ & $0.86[0.82-0.90]$ & $0.75[0.70-0.80]$ \\
\hline
\end{tabular}


Table 4: Percentage change in lipid parameters from the index date to week 12 in unmatched and propensity matched treatment groups.

\begin{tabular}{|c|c|c|c|c|c|c|c|}
\hline & \multicolumn{7}{|c|}{ Unmatched } \\
\hline & $\begin{array}{l}\text { Atorvastatin/ } \\
\text { ezetimibe ( } \mathrm{N}= \\
349)\end{array}$ & $\begin{array}{l}\text { Atorvastatin } \\
\text { monotherapy }(\mathrm{N} \\
=620)\end{array}$ & $\begin{array}{l}\text { Atorvastatin/ } \\
\text { ezetimibe }(\mathrm{N}= \\
349)\end{array}$ & $\begin{array}{l}\text { Atorvastatin } \\
\text { monotherapy (N } \\
=620)\end{array}$ & $\begin{array}{l}\text { Atorvastatin/ } \\
\text { ezetimibe }(\mathrm{N}= \\
349)\end{array}$ & $\begin{array}{l}\text { Atorvastatin } \\
\text { monotherapy ( } \mathrm{N} \\
=620)\end{array}$ & P value * \\
\hline & \multicolumn{2}{|c|}{ Index date: mean (SD) } & \multicolumn{2}{|c|}{ Week 12: mean (SD) } & \multicolumn{2}{|c|}{$\begin{array}{l}\text { Percentage change from index date to } \\
\text { week 12: mean (SD) }\end{array}$} & \\
\hline LDL-C & $157.5(38.7)$ & $142.2(30.0)$ & $73.6(25.9)$ & $83.4(23.9)$ & $-51.2(19.7)$ & $-40.2(16.7)$ & $<0.0001$ \\
\hline HDL-C & $52.1(13.3)$ & $51.1(12.9)$ & $51.7(13.8)$ & $50.9(13.7)$ & $0.3(17.6)$ & $0.8(18.0)$ & 0.881 \\
\hline Non-HDL-C & $185.1(40.9)$ & $169.7(34.9)$ & $92.8(30.7)$ & $103.7(27.4)$ & $-48.1(19.0)$ & $-37.6(16.6)$ & $<0.0001$ \\
\hline $\begin{array}{l}\text { Total } \\
\text { cholesterol }\end{array}$ & $237.3(43.4)$ & $220.7(37.7)$ & $144.5(31.8)$ & $154.6(29.3)$ & $-37.7(15.3)$ & $-29.0(13.0)$ & $<0.0001$ \\
\hline \multirow[t]{4}{*}{ Triglyceride } & $172.1(88.6)$ & $146.4(75.6)$ & $126.7(71.3)$ & $121.4(71.7)$ & $-16.1(48.9)$ & $-7.8(59.9)$ & 0.56 \\
\hline & \multicolumn{7}{|c|}{ Propensity matched } \\
\hline & $\begin{array}{l}\text { Atorvastatin/ } \\
\text { ezetimibe }(\mathrm{N}= \\
316)\end{array}$ & $\begin{array}{l}\text { Atorvastatin } \\
\text { monotherapy (N } \\
=316)\end{array}$ & $\begin{array}{l}\text { Atorvastatin/ } \\
\text { ezetimibe }(\mathrm{N}= \\
316)\end{array}$ & $\begin{array}{l}\text { Atorvastatin } \\
\text { monotherapy (N } \\
=316)\end{array}$ & $\begin{array}{l}\text { Atorvastatin/ } \\
\text { ezetimibe }(\mathrm{N}= \\
316)\end{array}$ & $\begin{array}{l}\text { Atorvastatin } \\
\text { monotherapy }(\mathrm{N} \\
=316)\end{array}$ & $\mathrm{P}$ value ${ }^{\wedge}$ \\
\hline & \multicolumn{2}{|c|}{ Index date: mean (SD) } & \multicolumn{2}{|c|}{ Week 12: mean (SD) } & \multicolumn{2}{|c|}{$\begin{array}{l}\text { Percentage change from index date to } \\
\text { week 12: mean (SD) }\end{array}$} & \\
\hline LDL-C & $151.1(33.6)$ & $151.4(29.8)$ & $72.4(25.7)$ & $85.8(25.0)$ & $-50.3(19.9)$ & $-42.7(15.0)$ & $<0.0001$ \\
\hline HDL-C & $51.9(13.3)$ & $51.6(12.7)$ & $51.6(13.9)$ & $51.8(13.8)$ & $0.4(17.7)$ & $1.5(19.1)$ & 0.468 \\
\hline Non-HDL-C & $179.7(37.8)$ & $177.0(31.9)$ & $91.9(30.6)$ & $105.2(29.0)$ & $-47.3(19.2)$ & $-39.8(15.7)$ & $<0.0001$ \\
\hline $\begin{array}{l}\text { Total } \\
\text { cholesterol }\end{array}$ & $231.6(40.1)$ & $228.6(34.5)$ & $143.5(31.5)$ & $157.0(29.9)$ & $-36.8(15.3)$ & $-30.7(12.3)$ & $<0.0001$ \\
\hline Triglyceride & $173.2(90.6)$ & $145.4(70.1)$ & $128.4(72.8)$ & $122.6(76.7)$ & $-15.3(50.0)$ & $-9.5(40.6)$ & 0.098 \\
\hline
\end{tabular}

\section{Discussion}

The current retrospective, real-world chart review study of statin-naive patients with hypercholesterolemia showed that a combination of atorvastatin and ezetimibe was superior to atorvastatin alone in achieving LDL-C goals after 12 weeks of treatment. Treatment groups were propensity matched to reduce selection bias due to confounding variables including age, sex, baseline LDL-C, risk classification, diabetes and other comorbidities. The primary efficacy outcome - the goal attainment rate - was significantly higher in the atorvastatin/ezetimibe group than in the atorvastatin monotherapy group $(p=0.0004)$. These results are consistent with those reported in randomized controlled trials (RCTs) of patients with hypercholesterolemia, with atorvastatin/ezetimibe producing significantly higher LDL-C goal attainment rates than atorvastatin alone [18-20].

Hypercholesterolemia is a key risk factor for CVD and, despite the wide availability of lipid-lowering therapy, few very highrisk (e.g. stable CHD or hospitalized for an ACS) patients achieve LDL-C target levels. Data from the international, observational, cross-sectional DYSIS II study showed that fewer than onethird of patients with stable CHD achieved an LDL-C level $<70$ $\mathrm{mg} / \mathrm{dL}$, despite all patients being at very high CV risk [21], and these findings were replicated within Asian DYSIS II cohorts [8, 9 , 22]. Other cross-sectional and real-world evidence clearly demonstrates that many CHD patients with dyslipidemia remain inadequately treated with most patients on statin therapy not achieving treatment targets [23-28]. Collectively, these findings indicate huge potential to improve cardiovascular outcomes using more intensive lipid-lowering therapy.

In the current real-world study, atorvastatin/ezetimibe also produced statistically significantly greater decreases in LDL-C, total cholesterol, and non-HDL-C levels compared with atorvastatin monotherapy. Significant differences were found by ANCOVA tests on unmatched data and paired t-tests for propensity matched data. These results demonstrate the greater LDL-C-lowering effect of atorvastatin/ezetimibe than atorvastatin monotherapy. Results obtained from RCTs for patients with hypercholesterolemia have consistently shown that 
atorvastatin/ezetimibe produced significantly greater reductions in LDL-C and triglycerides than atorvastatin monotherapy, with significant improvement in other lipid profiles reported less consistently during comparisons of the two treatment modalities $[10,18-20]$.

A 12-week RCT in patients with primary hypercholesterolemia reported that atorvastatin/ezetimibe significantly reduced LDL-C, total cholesterol, triglycerides and non-HDL-C, and significantly increased HDL-C compared with atorvastatin alone [10] although, in a 12-month extension, significant differences between the two treatment groups were only found for reductions in LDL-C, total cholesterol and triglyceride levels [18]. A combination of atorvastatin plus ezetimibe significantly reduced levels of LDL-C, triglycerides, and non-HDL-C at 4 weeks in patients with heterozygous familial hypercholesterolemia compared to atorvastatin alone [19].

In a RCT of hypercholesterolemic patients with CHD, a combination of atorvastatin plus ezetimibe led to significantly greater reductions in LDL-C, total cholesterol, triglycerides and non-HDL-C, and significantly increased HDL-C, at 6 weeks compared to atorvastatin/placebo [20]. In the current study, subgroup analysis of hypercholesterolemic patients with diabetes failed to show any significant differences between atorvastatin/ ezetimibe and atorvastatin monotherapy in achieving LDL-C goals or improving lipid parameters. These analyses were limited by the failure to enroll the planned number of diabetic patients in the atorvastatin/ezetimibe group with consequent reductions in power.

Limitations of this observational study, which is based on a retrospective chart review, include potential bias caused by confounding effects due to the lack of randomization. These effects are likely to be minimized following propensity matching of patients but cannot be ruled out entirely. In the current study, we matched the atorvastatin/ezetimibe and atorvastatin groups on recognized CV risk factors. Consequently, half of the atorvastatin group were excluded and the results are only applicable to patients with the characteristics of the atorvastatin/ ezetimibe group rather than being generalizable to all patients. When we conducted propensity score matching, baseline LDL levels were significantly different between the two groups before matching. Thus, many patients with low baseline LDL levels in the atorvastatin group were excluded in the matching process. This represents a limitation of the study and is also a problem for other comparative studies in which patients are not randomized. Due to the shorter time period of market availability for atorvastatin/ ezetimibe than atorvastatin, the number of enrolled patients in the combination treatment group was lower than planned, reducing the power of the study, most notably in the diabetic patient subgroup, as discussed above.

Despite these limitations, this study provides a meaningful comparison of LDL-C goal attainment rates with atorvastatin/ ezetimibe and atorvastatin monotherapy in Korean patients with hypercholesterolemia in a real-world clinical practice setting, complementing existing evidence obtained from RCTs. Atorvastatin/ezetimibe, a dual fixed-dose combination tablet for the primary treatment of hypercholesterolemia had greater efficacy than atorvastatin alone. This study is expected to serve as a useful reference for the establishment of dyslipidemia treatment guidelines in Korean patients.

\section{Acknowledgements}

The authors thank Robert A. Furlong PhD and David P. Figgitt PhD, ISMPP CMPP ${ }^{\mathrm{TM}}$, Content Ed Net, for providing medical writing assistance, with funding from Merck Sharp \& Dohme Corp., Seoul, South Korea. The authors also thank LSK Global Pharma Services Co., Ltd. for data analysis, with funding from Merck Sharp \& Dohme Corp., Seoul, South Korea.

\section{Funding}

The study was funded by Merck Sharp \& Dohme Corp., Seoul, Korea.

\section{Compliance with Ethical Standards}

\section{Conflict of Interest}

NA

\section{Ethical Approval}

Approval was obtained by all study sites from the appropriate institutional review board (IRB) or ethics review committee (ERC) for the finalised protocol and other study documents. The study was conducted in accordance with Good Pharmacoepidemiology Practice (GPP) guidelines and national and/or regional laws and regulations for the protection of subjects participating in biomedical studies.

As this was a retrospective chart review study using data extracted from medical records, no on-site visit by patients was required, and no direct patient identifiers (e.g. name or medical record number) were collected. In addition, the study neither provided drugs nor collected biological samples. Consequently, a waiver of patient consent was granted by IRBs.

$\begin{array}{ll}\text { Abbreviations } & \\ \text { DBP: } & \text { Diastolic blood pressure } \\ \text { HDL-C: } & \text { High-density lipoprotein cholesterol } \\ \text { KNHANES: } & \text { Korea National Health and Nutrition Survey } \\ \text { KSLA: } & \text { Korean Society of Lipidology and } \\ \text { Atherosclerosis } & \\ \text { LDL-C: } & \text { Low-density lipoprotein cholesterol } \\ \text { SBP: } & \text { Systolic blood pressure }\end{array}$




\section{References}

1. Roth GA, Johnson C, Abajobir A, Abd-Allah F, Abera SF, Abyu G, et al. Global, regional, and national burden of cardiovascular diseases for 10 causes, 1990 to 2015. J Am Coll Cardiol. 2017;70(1):1-25. doi: 10.101 6/ j.j acc. 2017.04 .052

2. Lee SW, Kim HC, Lee HS, Suh I. Thirty-year trends in mortality from cardiovascular diseases in Korea. Korean Circ J. 2015;45(3):202-209. doi: 10.4070/kcj.2015.45.3.202

3. Grundy SM, Stone NJ, Bailey AL, Beam C, Birtcher KK, Blumenthal RS, et al. 2018 AHA/ ACC/ AACVPR/ AAPA/ ABC/ ACPM/ADA/AGS/ APhA/ASPC/NLA/PCNA Guideline on the Management of Blood Cholesterol: Executive Summary: A Report of the American College of Cardiology/American Heart Association Task Force on Clinical Practice Guidelines. J Am Coll Cardiol. 2019;73(24): 3168-3209. doi: 10.1016/j.jacc.2018.11.002.

4. Lee J, Son H, Ryu OH. Management status of cardiovascular disease risk factors for dyslipidemia among Korean adults. Yonsei Med J. 2017;58(2):326-338. doi: 10.3349/ymj.2017.58.2.326.

5. National Cholesterol Education Program (NCEP) Expert Panel on Detection, Evaluation, and Treatment of High Blood Cholesterol in Adults (Adult Treatment Panel III). Third Report of the National Cholesterol Education Program (NCEP) Expert Panel on Detection, Evaluation, and Treatment of High Blood Cholesterol in Adults (Adult Treatment Panel III) final report. Circulation. 2002;106(25):31433421.

6. Jeong JS and Kwon HS. Prevalence and clinical characteristics of dyslipidemia in Koreans. Endocrinol Metab (Seoul). 2017;32(1):3035. doi: 10.3803/EnM.2017.32.1.30.

7. Poh KK, Ambegaonkar B, Baxter CA, Brudi P, Buddhari W, Chiang FT, et al. Low-density lipoprotein cholesterol target attainment in patients with stable or acute coronary heart disease in the Asia-Pacific region: results from the Dyslipidemia International Study II. Eur J Prev Cardiol. 2018;25(18):1950-1963. doi: 10.1177/2047487318798927.

8. Lee SH, Jeong MH, Cho JM, Kang SH, Jur SH, Jeon DW, et al. Prevalence of lipid abnormalities among treated patients with stable CHD: The Dyslipidemia International Study (DYSIS) II South Korea results. Atherosclerosis. 2015; 241(1):e131-132. doi:10.1016/j. atherosclerosis.2015.04.455

9. Gitt AK, Lautsch D, Ferrières J, De Ferrari GM, Vyas A, Baxter CA, et al. Contemporary data on treatment practices for low-density lipoprotein cholesterol in 3867 patients who had suffered an acute coronary syndrome across the world. Data Brief. 2017;16:369-375. doi: 10.1016/j.dib.2017.11.034.

10. Ballantyne CM, Houri J, Notarbartolo A, Melani L, Lipka LJ, Suresh R, et al. Effect of ezetimibe coadministered with atorvastatin in 628 patients with primary hypercholesterolemia: a prospective, randomized, double-blind trial. Circulation. 2003;107(19):2409-2415.

11. Giugliano RP, Wiviott SD, Blazing MA, De Ferrari GM, Park JG, Murphy $\mathrm{SA}$, et al. Long-term safety and efficacy of achieving very low levels of low-density lipoprotein cholesterol: A Prespecified analysis of the IMPROVE-IT trial. JAMA Cardiol. 2017;2(5):547-555. doi: 10.1001/ jamacardio.2017.0083.

12. Committee for the Korean Guidelines for the Management of
Dyslipidemia. 2015 Korean Guidelines for the Management of Dyslipidemia: Executive Summary (English Translation). Korean Circ J. 2016;46(3):275-306. doi: 10.4070/kcj.2016.46.3.275

13. Stuart EA. Matching methods for causal inference: A review and a look forward. Stat Sci. 2010;25(1):1-21.

14. Davidson MH, Ballantyne CM, Kerzner B, Melani L, Sager PT, Lipka L, et al. Efficacy and safety of ezetimibe coadministered with statins: randomised, placebo-controlled, blinded experience in 2382 patients with primary hypercholesterolemia. Int J Clin Pract. 2004;58(8):746755.

15. Farsang C, Athyros V, Gaw A; ACTFAST-2 investigators and Steering Committee members. A multicentre, open study to assess the effect of individualizing starting doses of atorvastatin according to baseline LDL-C levels on achieving cholesterol targets: the Achieve Cholesterol Targets Fast with Atorvastatin Stratified Titration (ACTFAST-2) study. Curr Med Res Opin. 2007;23(8):1945-1956.

16. McKenney JM, Davidson MH, Saponaro J, Thompson PD, Bays HE. Use of a treatment algorithm to achieve NCEP ATP III goals with atorvastatin. J Cardiovasc Pharmacol. 2005;46(5):594-599.

17. Cannon CP, Blazing MA, Giugliano RP, McCagg A, White JA, Theroux P, et al. Ezetimibe Added to Statin Therapy after Acute Coronary Syndromes. N Engl J Med. 2015;372(25):2387-2397. doi: 10.1056/ NEJMoa1410489.

18. Ballantyne CM, Lipka LJ, Sager PT, Strony J, Alizadeh J, Suresh R, et al. Long-term safety and tolerability profile of ezetimibe and atorvastatin coadministration therapy in patients with primary hypercholesterolaemia. Int J Clin Pract. 2004;58(7):653-658.

19. Stein E, Stender S, Mata P, Sager P, Ponsonnet D, Melani L, et al. Achieving lipoprotein goals in patients at high risk with severe hypercholesterolemia: efficacy and safety of ezetimibe coadministered with atorvastatin. Am Heart J. 2004;148(3):447-455.

20. Cruz-Fernández JM, Bedarida GV, Adgey J, Allen C, Johnson-Levonas AO, Massaad R. Efficacy and safety of ezetimibe co-administered with ongoing atorvastatin therapy in achieving low-density lipoprotein goal in patients with hypercholesterolemia and coronary heart disease. Int J Clin Pract. 2005;59(6):619-627.

21. Gitt AK, Lautsch D, Ferrières J, De Ferrari GM, Vyas A, Baxter CA, et al. Cholesterol target value attainment and lipid-lowering therapy in patients with stable or acute coronary heart disease: Results from the Dyslipidemia International Study II. Atherosclerosis. 2017;266:158166. doi: 10.1016/j.atherosclerosis.2017.08.013.

22. Yan BP, Chiang FT, Ambegaonkar B, Brudi P, Horack M, Lautsch D, et al. Low-density lipoprotein cholesterol target achievement in patients surviving an acute coronary syndrome in Hong Kong and Taiwan findings from the Dyslipidemia International Study II. Int J Cardiol. 2018;265:1-5. doi: 10.1016/j.ijcard.2018.01.099.

23. Marrett E, Zhao C, Zhang NJ, Zhang Q Ramey DR, Tomassini JE, et al. Limitations of real-world treatment with atorvastatin monotherapy for lowering LDL-C in high-risk cardiovascular patients in the US. Vasc Health Risk Manag. 2014;10:237-46. doi: 10.2147/VHRM.S54886.

24. Reiner Ž, De Backer G, Fras Z, Kotseva K, Tokgözoglu L, Wood D, et al. Lipid lowering drug therapy in patients with coronary heart disease from 24 European countries--Findings from the EUROASPIRE 
IV survey. Atherosclerosis. 2016;246:243-250. doi: 10.1016/j. atherosclerosis.2016.01.018.

25. Kuiper JG, Sanchez RJ, Houben E, Heintjes EM, Penning-van Beest FJA, Khan I, et al. Use of lipid-modifying therapy and LDL-C goal attainment in a high-cardiovascular-risk population in the Netherlands. Clin. Ther. 2017;39(4):819-827.e1. doi: 10.1016/j.clinthera.2017.03.001.

26. Steen DL, Khan I, Ansell D, Sanchez RJ, Ray KK. Retrospective examination of lipid-lowering treatment patterns in a real-world highrisk cohort in the UK in 2014: comparison with the National Institute for Health and Care Excellence (NICE) 2014 lipid modification guidelines. BMJ Open. 2017;7(2):e013255. doi: 10.1136/bmjopen-2016-013255.

27. März W, Dippel FW, Theobald K, Gorcyca K, Iorga ȘR, Ansell D. Utilization of lipid-modifying therapy and low-density lipoprotein cholesterol goal attainment in patients at high and very-high cardiovascular risk: Real-world evidence from Germany. Atherosclerosis. 2018;268:99107. doi: 10.1016/j.atherosclerosis.2017.11.020.

28. Breuker C, Clement F, Mura T, Macioce V, Castet-Nicolas A, Audurier $\mathrm{Y}$, et al. Non-achievement of LDL-cholesterol targets in patients with diabetes at very-high cardiovascular risk receiving statin treatment: Incidence and risk factors. Int J Cardiol. 2018;268:195-199. doi: 10.1016/j.ijcard.2018.04.068. 